\title{
Experimental study of safety supply flow rate on a small bore cylindrical journal sliding bearing
}

小ロ径ジャーナルすべり軸受における安定化流量の実験的検討

\author{
Yuta NARUSE \\ Graduate School of Mechanical Engineering, Tokai University, 4-1-1 Kitakaname, Hiratsuka, \\ Kanagawa, 259-1292 Japan \\ TEL: +81-463-58-1211(EX.4364) FAX: +81-463-59-2207 e-mail: 2bmkm040@mail.tokai-u.jp \\ Masayuki OCHIAI \\ Mechanical Engineering, Tokai University, 4-1-1 Kitakaname, Hiratsuka, Kanagawa, 259-1292 \\ Japan \\ TEL: +81-463-58-1211(EX.4346) FAX: +81-463-59-2207 e-mail: ochiaim@ keyaki.cc.u-tokai.ac.jp \\ (Received 30 April, $2013 \quad$ Accepted 29 May, 2013)
}

The effects of temperature distribution and external vibration on stabilized supply flow rate of small bore journal sliding bearing were experimentally investigated. Journal sliding bearings are used widely in many rotational machineries such as engine, turbine, HDD etc.. However, journal sliding bearings generate oilwhip under high speed operation. In order to solve this problem, Hashimoto suggested a stabilization method for suppressing oilwhip by using starved lubrication in which supply oil rate is reduced. However, the starved lubrication have the risks of sudden rising of temperature and regenerating oilwhip caused by external vibrations. In this study, the temperature distribution around the axis and the effect of the external vibrations was investigated to make clear the behavior of the oil. The temperature distributions were measured with thermocouples and cavitations generating in the bearing clearance were visualized by using a high-speed camera. In addition, the vibration test was carried out with an impulse hammer and an acceleration sensor. The area was observed for the temperature to increase rapidly from the results of reducing supply of flow rate. In addition, in the case of increasing supply frow rate, the difference between the maximum temperature and minimum temperature in the bearing is reduced gradually. Moreover, the oil whip was occurred by the external vibration. It was found that both risks were possible to avoid by adjusting the supply flow rate adequately.

Keywords : Oil whip, Journal sliding bearing, Temperature distribution, Stability, Cavitation, External vibration.

\section{INTRODUCTION}

ジャーナルすべり軸受は，軸と軸受を非接触で支持す るため耐摩耗性に優れており, 火力・水力・原子力用の 発電タービン, ハードディスクドライブなど, 数多くの 回転機械に用いられている，近年，省エネルギー化・省

SAS Award was given to this paper presented as Poster Presentation at the 2012 SAS Intelligent Symposium.
スペース化の指向から回転機械は小型化・高速化の傾向 にある.しかし，ジャーナルすべり軸受では高速回転時に オイルホイップと呼ばれる自励振動が発生し，軸と軸受 が接触し，破壊に至る危険性がある．現在オイルホイッ プの抑制方法としてティルティングパッド軸受が広く用 いられているが，同軸受は形状が複雑であるためコスト が高く小型化に不向きという問題がある. 
このような問題に対して橋本らは，軸受に供給する潤 滑油量を減少させるスターブ潤滑を用いたオイルホイッ プの抑止法を考案し, 1 小口径真円ジャーナルすべり軸 受において高速回転時に高い安定性を有することを理論 および実験の両面から明らかにしてきた.しかしながら， スターブ潤滑下では潤滑油量の減少により油膜厚さが薄 くなるため，急激に温度が上昇し焼付きを起こす危険性 が高まる。

これまで，ジャーナルすべり軸受内の温度分布に関す る研究は数多く行われてきた. 例えば杉本らは, 軸受内 における油膜温度分布と軸荷重, 潤滑油の粘度の関係に ついて研究している. 2 その中で, 軸受内で局所的に潤 滑油の温度が上昇することや, 軸荷重および潤滑油の粘 度の増加に伴い潤滑油の温度が高くなることを実験的に 明らかにしている。.また，三井らはジャーナルすべり軸 受の温度特性に関して, 様々な運転条件下における熱発 生とその放熱方法について論じている. ${ }^{3,4}$ その過程で軸 回転数および偏心率が軸受面の温度分布に与える影響や 給油条件と温度上昇の関係, 潤滑油の特性による軸受温 度特性の違い等の基本的な特性を明らかにしている。一 方田中らは，定常状態にある層流の潤滑油膜に限定し， 熱伝達モデルによる熱流体潤滑理論の定式化と数值解析 法について検討している. 5,6 しかし，いずれの研究にお いてもスターブ潤滑下における温度分布の測定は行われ ておらず，軸回転数も 500〜 4000[rpm]程度の運転条件で ある.さらに軸受のサイズも大型のもので小型化を念頭 においた条件下での温度分布測定例は数少ない. また, キャビテーションが軸受特性に関わることが知られてお り

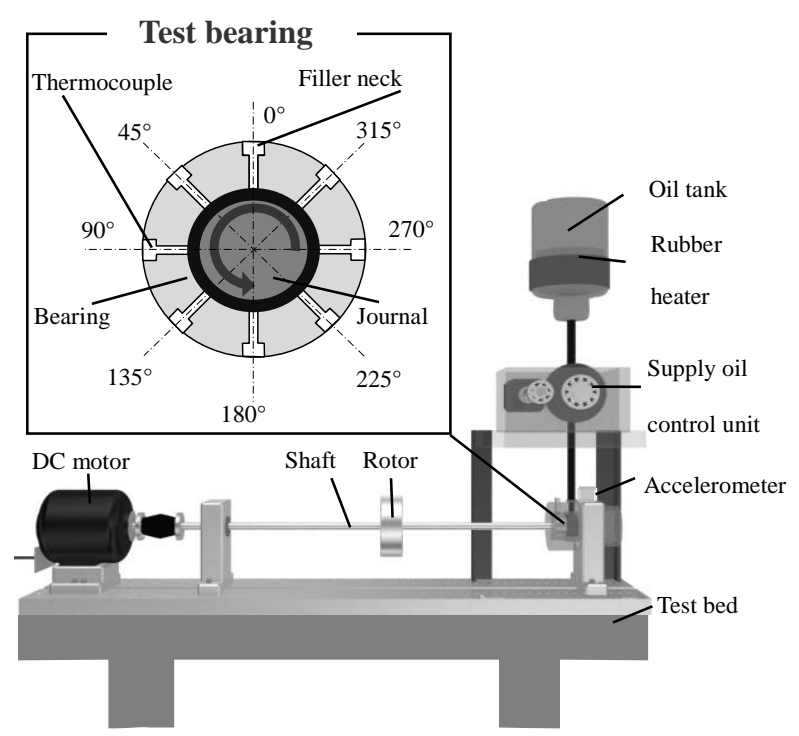

Fig. 1. Experimental setup.
その可視化に関する研究が過去にいくつか行われている が，7,8 温度分布とキャビテーションの発生状況を比較し て，その関係性について論じている研究は我々の知る限 り見受けられない。一方で，オイルホイップ状態から供 給流量を絞りオイルホイップが収まる時の供給流量とス ターブ潤滑から供給流量を増加させオイルホイップが起 きる時の流量にはヒステリシスの関係があることが著者 らの過去の研究より明らかになっている，9この現象を 利用することでスターブ潤滑下においても軸受内油膜厚 さを確保でき, 軸受内の温度上昇を抑えることが期待で きる。しかし，地震等に起因した外乱などが加わった場 合には，再びオイルホイップが生じて不安定化する恐れ がある。

このような背景の下，本研究ではスターブ潤滑下にお いて小口径ジャーナルすべり軸受内の温度分布測定とキ ヤビテーションの可視化実験を同時に行い，軸受内温度 分布の発生原因を考察した。また，供給流量を変化させ て加振実験を行い，外部振動が作用した際の小口径ジャ 一ナル軸受の安全性について検討したので報告する.

\section{MATERIALS}

本実験に用いた小型軸受試験装置を Fig. 1 に示す。試 験軸受は真円軸受で，寸法は軸受直径 $D=25[\mathrm{~mm}]$, 軸受 幅 $L=14.5[\mathrm{~mm}]$, クリアランス $C r=0.175[\mathrm{~mm}]$ であり，軸 受にかかる荷重は 4.24[N]である．また，試験軸受の材質 を透明アクリルにすることでキャビテーションの可視化 を可能としている.

潤滑油はオイルタンクから軸受部（挿入穴 $0^{\circ}$ ) へと供 給され，供給流量は流量制御装置を用いることで自動で 調整することが可能である。また，オイルタンクにはラ バーヒータが取り付けられており，潤滑油温度を任意に 調節することができる．なお，潤滑油は ISOVG22 を用 いている.

温度分布測定は， 7 本のシース熱電対を試験軸受周り に 45間隔で取り付けて行った. 熱電対の取り付けには 専用の治具を用い，治具内部には油もれ防止のためにシ

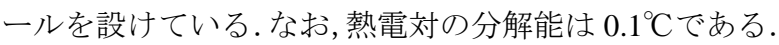
また，キャビテーションの可視化は高速度カメラを用い た. 使用した高速度カメラの分解能は 720×640[pixel]であ り，撮影速度は 3000[fps]とした．加振実験の際には，試 験台を下方向からインパルスハンマーを用いて装置全体 を加振し，軸受上部に取り付けた加速度センサーにより 加速度の測定を行った。 


\section{METHODS}

Figure 2 に本実験で実施した 2 種類の安定臨界流量 $Q_{c}$ の決定方法を示す. Figure 2(a)はオイルホイップ発生状態 から供給流量を減らし, 安定化した際の供給流量(以降, 減少時臨界流量）を，Figure 2(b)はスターブ潤滑下の安 定状態から供給流量を増やし，オイルホイップが発生す る直前の供給流量（以降, 増加時臨界流量）を測定する 方法である. 以上のような 2 種類の供給流量の条件下に て, 温度分布測定とキャビテーション可視化実験, 及び 加振実験を行った.

なお，キャビテーションの可視化実験では，最小供給流 量, 減少時臨界流量及び増加時臨界流量の 3 条件下にお いて高速度カメラを用いて撮影を行った。 また，加振実 験では, 各供給流量において装置全体にかかる加振力を 徐々に大きくし，オイルホイップが発生する加速度を
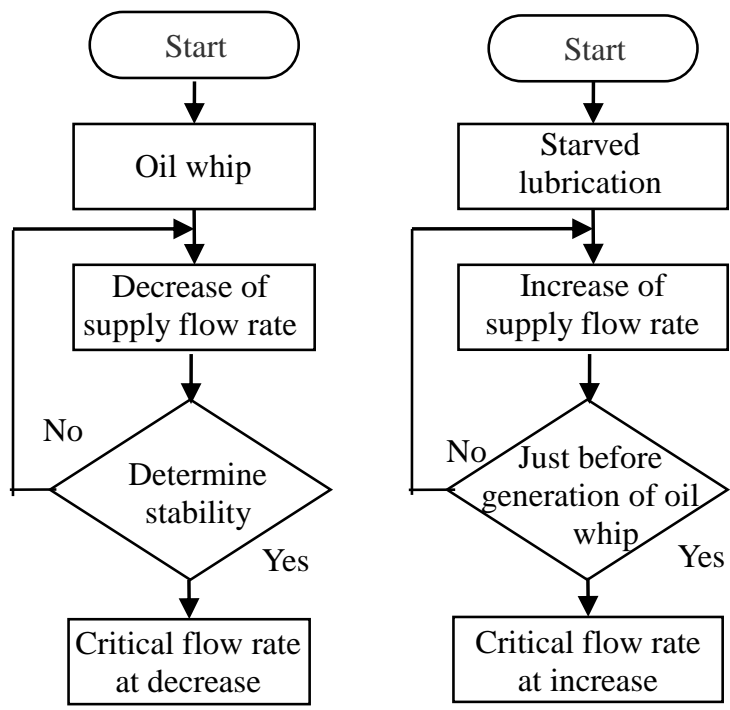

(a) Case of decreasing supply flow rate (b) Case of increasing supply flow rate
オイルホイップ発生加速度として測定した。

本実験では安全性を考慮して最小供給流量を $0.23 \times 10^{-6}\left[\mathrm{~m}^{3} / \mathrm{s}\right]$ とし，装置全体にかかる加速度の上限を $10\left[\mathrm{~m} / \mathrm{s}^{2}\right]$ とした。供給油温を $40\left[{ }^{\circ} \mathrm{C}\right]$ とし，軸回転数を $7500[\mathrm{rpm}]$ とした。

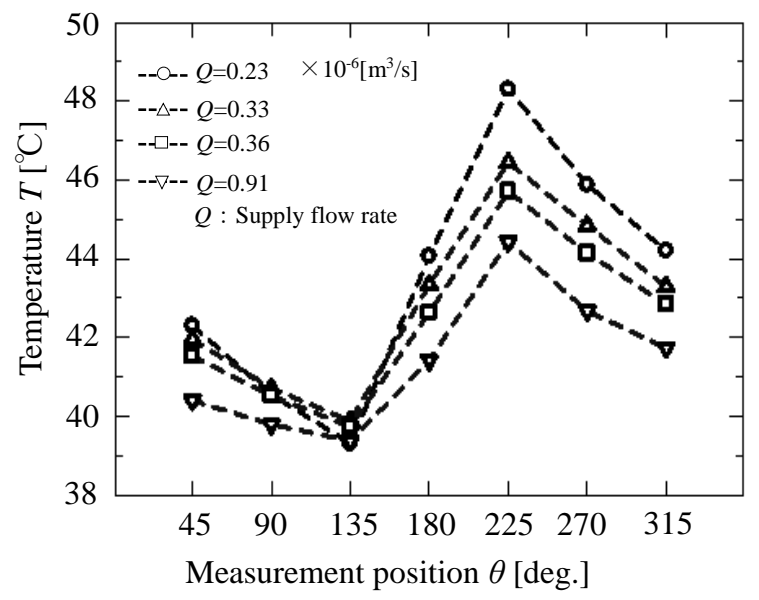

Fig. 3. Temperature distribution under decreasing supply flow rate condition.

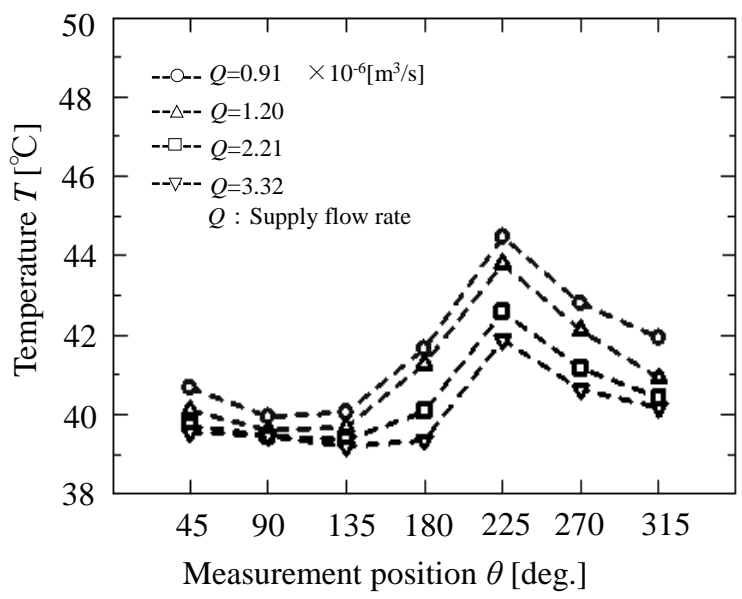

Fig. 4. Temperature distribution under increasing supply flow rate condition. critical supply flow rate.

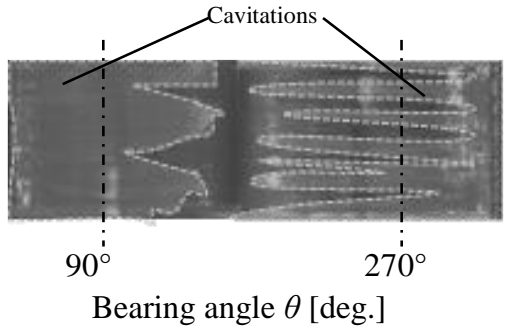

(a) Minimum supply flow rate $\left(Q c=0.23 \times 10^{-6}\left[\mathrm{~m}^{3} / \mathrm{s}\right]\right)$

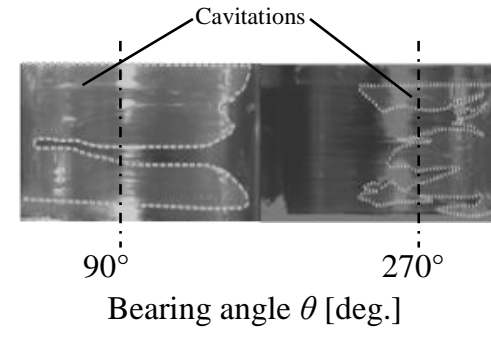

(b) Critical supply flow rate under decreasing condition $\left(Q c=0.91 \times 10^{-6}\left[\mathrm{~m}^{3} / \mathrm{s}\right]\right)$

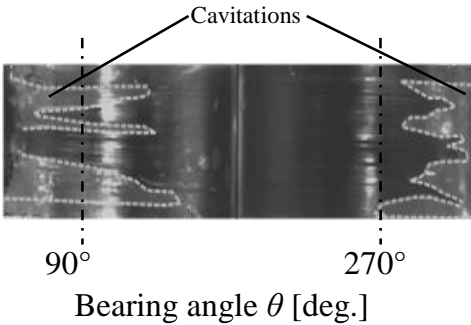

(c) Critical supply flow rate under increasing condition $\left(Q c=3.56 \times 10^{-6}\left[\mathrm{~m}^{3} / \mathrm{s}\right]\right)$

Fig. 5. Visualization results of cavitations. 


\section{RESULTS}

Figure 3 は減少時臨界流量から供給流量を減少させた ときの軸受内温度分布を, Fig. 4 は減少時臨界流量から 供給流量を増加させたときの軸受内温度分布をそれぞれ 示している。 また，Fig. 5(a)〜(c)はそれぞれ最小供給流 量, 減少時臨界流量及び増加時臨界流量におけるキャビ テーション画像を表している. 破線で囲まれた領域がキ ヤビテーション領域を示しており, それ以外の部分は油 膜領域を示している.

Figure 3 より, それぞれの供給流量において, 温度測 定位置 $45^{\circ}$ から $135^{\circ}$ および $275^{\circ}$ から $315^{\circ}$ の領域で軸受す きま内の温度が低下寸る傾向にあることが見て取れる.

これは Fig. 5(a)及び Fig. 5(b)に示すように, 軸受すきま内 においてキャビテーションが発生し，軸受すきま内の流 れが空気と油の混層流状態となるため油に満たされてい る場合に比べて粘性摩擦による発熱が抑えられ，温度が 低下したものと考えられる，一方，135から $270^{\circ}$ 付近で は温度が上昇している。これは $135^{\circ}$ から $270^{\circ}$ 付近におい て油膜領域となるため, せん断摩擦による発熱の影響が 大きくなったためと考えられる. Figure 4 においても Fig. 3 とほぼ同様の傾向が見て取れるが 135 付近から温度が 上昇する傾向が異なる. また, 軸受内温度分布の差異も 小さくなっていることがわかる. その原因は, 軸受内一 の供給流量が増加するため, 潤滑油による冷却効果が高 くなることに加え, Fig. 5(c)のキャビテーション画像から わかるように油膜厚さが広い領域で確保されたことによ り油膜のせん断摩擦による発熱が生じにくくなったため と考えられる.

Figure 6 は, 軸受内最高温度と最低温度及び加振実験 によるオイルホイップ発生加速度と臨界流量の関係を示 している.減少時臨界流量以下の領域に着目してみると, 軸受内の温度は供給流量が $0.5 \times 10^{-6}\left[\mathrm{~m}^{3} / \mathrm{s}\right]$ 付近から急激 に上昇する傾向が見て取れる。また，それに伴い軸受内 最高温度と最低温度の差も大きくなっている. なお，こ の領域においては, 加振実験によるオイルホイップの発 生は確認されなかった。 次に減少時臨界流量以上の領域 に着目してみると, オイルホイップ発生直前までは供給 流量の増加に伴い軸受内最高温度は低下しているが，才 イルホイップが発生すると, 軸受内最高温度及び最低温 度の双方で温度上昇することが見て取れる。

一方，加振実験の結果より，供給流量が増加するにつ れて線形的にオイルホイップが発生する加速度が小さく なっていることがわかる, その原因は, 供給流量が増加 するにつれて軸受内の油膜が厚くなり, 油膜反力の連成 ばね成分が増加するためだと考えられる。

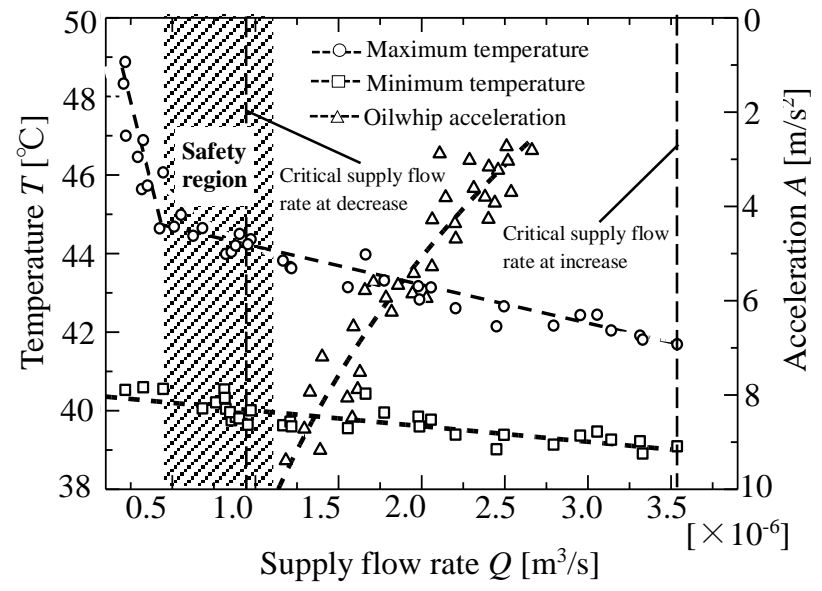

Fig. 6. Temperature distribution and oil whip acceleration with supply flow rate.

以上の結果より，供給流量が減少すると軸受内で急激 に温度上昇する領域があり，一方で供給流量が増加する と，外乱によりオイルホイップが発生する領域がある. しかし，同図中に示すように安全な流量領域が存在する ことから，供給流量を適切に調節することで，これら両 方の危険性を回避することができると考えられる.

\section{CONCLUSION}

小口径ジャーナルすベり軸受において，スターブ潤滑 下での温度分布測定とキャビテーションの可視化実験お よび加振実験を行った。 その結果，減少時臨界流量から 供給流量を徐々に減少させた場合においては軸受内の温 度上昇が小さい供給流量領域が存在することがわかった。 また, 減少時臨界流量から供給流量を徐々に増加させた 場合においては，外部振動によりオイルホイップが発生 する危険性があることが確認された。しかし，供給流量 を適切に選定することにより外部振動による不安定化と 急激な温度上昇を同時に回避し得ることが確かめられた。

\section{REFERENCES}

${ }^{1}$ H. Hashimoto and M. Ochiai, Journal of Tribology ASME, 132, 1, pp.1-7 (2010).

2 Y. Sugimoto, Transactions of the Japan Society of Mechanical Engineers, 14, 47, pp.II-1-II-8 (1948)

3 J. Mitsui, Transactions of the Japan Society of Mechanical Engineers, 49, 438, pp.199-208 (1983).

${ }^{4}$ J. Mitsui, Y. Hori and M. Tanaka, Transactions of the ASME Journal of Lubrication Technology, 105, 3, pp.414-421(1983).

${ }^{5}$ M. Tanaka and K. Hatakenaka, Journal of Japanese Society of Tribologists, 49, 9, pp.36-41 (2004). 
${ }^{6}$ K. Hatakenaka, M. Tanaka and K. suzuki, Journal of Japanese Society of Tribologists, 45, 8, pp.628-635 (2000).

7 M. Noma and A. Mori, Journal of the Visualization Society of Japan, 23， 10, pp.93-99 (2003).
${ }^{8}$ H. Mori, S. Miyata and Y. Abe, Transactions of the Japan Society of Mechanical Engineers, 33， 248, pp.658-666 (1967).

9 Y. Sunami, H. Hashimoto and M. Ochiai, Proceedings of JAST Tribology Conference, 5, pp.103-104 (2011). 